\title{
Activated Marrow Infiltrating Lymphocytes
}

National Cancer Institute

\section{Source}

National Cancer Institute. Activated Marrow Infiltrating Lymphocytes. NCI Thesaurus.

Code C111759.

A preparation of cells, which consists of autologous marrow infiltrating lymphocytes

(MILS), that are manipulated in vitro, with potential antitumor and immune stimulating activities. MILs are harvested from autologous bone marrow from multiple myeloma patients and, in vitro, are exposed to and activated by anti-CD3/anti-CD28 monoclonal antibodies covalently attached to super-paramagnetic microbeads. After removal of the beads and expansion of the cells in culture, the activated MILs (aMILs) are re-introduced into the patient. The aMILs possess enhanced myeloma specificity, and are able to infiltrate the tumor microenvironment and initiate tumor cell lysis. CD3 and CD28, costimulatory molecules expressed on the surface of T-lymphocytes, play a key role in the activation of T-cells. 